\title{
Tek ve Çift Doz Aşı Uygulamalarının COVID-19 Vaka Sayıları Üzerinden Benzetim Yöntemiyle Karşıış̧ırılması
}

\section{Comparison Between One and Two Dose Vaccine Applications Based on COVID-19 Cases with Simulation Method}

\author{
Mustafa Demirbilek ${ }^{1}$ iD \\ ${ }^{1}$ Gaziantep İslam Bilim ve Teknoloji Üniversitesi, Mühendislik ve Doğa Bilimleri Fakültesi, Endüstri Mühendisliği Bölümü, 27260 Şahinbey \\ Gaziantep
}

Başvuru/Received: 23/09/2021

Kabul / Accepted: 14/11/2021

Çevrimiçi Basım / Published Online: 15/01/2022

Son Versiyon/Final Version: 15/01/2022

\begin{abstract}
$\ddot{\mathbf{O} z}$
Çin'in Wuhan şehrinde başlayan COVID-19 salgını yaklaşık bir buçuk yıllık bir sürede dünyayı etkisi altına almış, milyonlarca insanın hastalanmasına ve ölmesine, ekonomik faaliyetlerde büyük kayıplara neden olmuştur. Geçmişte diğer salgınların durdurulmasında kullanıldığı gibi COVID-19 salgınını durdurmak için kullanılacak en etkili müdahale stratejisi aşılamadır. Aşı geliştirme çalışmaları salgınla beraber başlamasına rağmen üretilen aşı sayısı toplumlar için hala çok yetersizdir. Kıt aşı miktarı ve tek doz aşı uygulamasının bireylerde belli ölçüde koruma sağlayabilmesi, iki doz halinde aşı uygulamasının birçok platformda eleştirilmesine yol açmıştır. Bu çalışmada farklı etkinlik düzeyleri, aşı miktarları ve dağıtım zamanları düşünülerek, Biontech aşısının tek ve çift doz halinde uygulanması, vaka sayıları üzerinden karşılaştırılmıştır. Salgının modellenmesinde, bireylerin diğer bireylerle, sadece ev, iş yeri ve okul gibi ortamlarda direkt etkileşim içinde, kalan bireylerle endirekt etkileşim içinde olabileceği SIR (Korunmasız-Hasta-Iyileşen) Ağ modeli kullanılmıştır. Bir yıllık salgın süreci ve bir milyon kişilik popülasyonun düşünüldüğü modelde, tek ve çift doz aşı uygulama üzerine oluşturulan her senaryo için 30 koşum yapılmış ve sonuçlar arasındaki farklılıklar bağımsız örneklem t testi kullanılarak analiz edilmiştir. Altmış günlük dağıtım zamanı için çift doz uygulama ile karşılaştırıldığında, tek doz aşı uygulaması tüm etkinlik seviyelerinde vaka sayılarını önemli oranda düşürmüştür.
\end{abstract}

Anahtar Kelimeler

"COVID-19, Aşılama, Benzetim, SIR Ă̆ Modelleri"

\begin{abstract}
COVID-19 pandemic started Wuhan city in China affected world for almost one and half years and caused millions of infected and death people and great loss in economic activities. The most effective intervention strategy is vaccination to stop COVID-19 pandemic as it stopped other pandemics in history. The number of shots produced so far is insufficient for societies even though studies for developing vaccines started with the pandemic. Insufficient number of vaccines and the reasonable level protection of one-dose shot on individuals caused widespread criticisms of applications of two doses. In this study, applications of one dose and two dose vaccines are compared based on the number of cases by considering different efficacy levels, the number of shots, and delivery periods. SIR (Susceptible-Infectious-Recovered) Network model where individuals can directly interact with others only in homes, schools, and workplaces while indirectly interacting with the remainings is used to mimic the pandemic. Thirty trials are conducted for each scenario included an application of one or two dose vaccines and independent sample $t$ tests are carried out to understand whether differences between results are statistically significant for the model a-year pandemic duration and a-million population are considered in. The application of one dose vaccine significantly decreases the number of cases compared to two doses for the 60-day delivery period.
\end{abstract}

Key Words

"COVID-19, Vaccination, Simulation, SIR Network Models" 


\section{Giriş}

Bulaşıcı hastalıklar tarih boyunca insanlığı etkilemiş, çok sayıda insanın hastalanmasına ve ölmesine ve devletler için büyük ekonomik kayıplara neden olmuştur. Tarihteki veba, sıtma, kolera gibi salgınların yanı sıra, yirminci yüzyılın en büyük salgını olan İspanyol gribi yaklaşık 50 milyon kişinin hayatına mal olarak, birinci dünya savaşında ölenlerin sayısını geçmiştir (Demirbilek, 2020). Yeni milenyumda ise SARS, MERS ve Ebola salgınları dünya genelinde birçok insanın hastalanmasına ve ölmesine sebep olmuştur. 2019 yılının aralık ayında ortaya çıkan ve daha sonra COVID-19 olarak adlandırılan virüsün neden olduğu salgın, şimdiye kadar dünya genelinde yaklaşık 167 milyon insanın hasta olmasına, vakalardan yaklaşık 3.5 milyonun ölmesine ve ekonomik olarak büyük bir daralmaya neden olmuştur (Şekil 1).
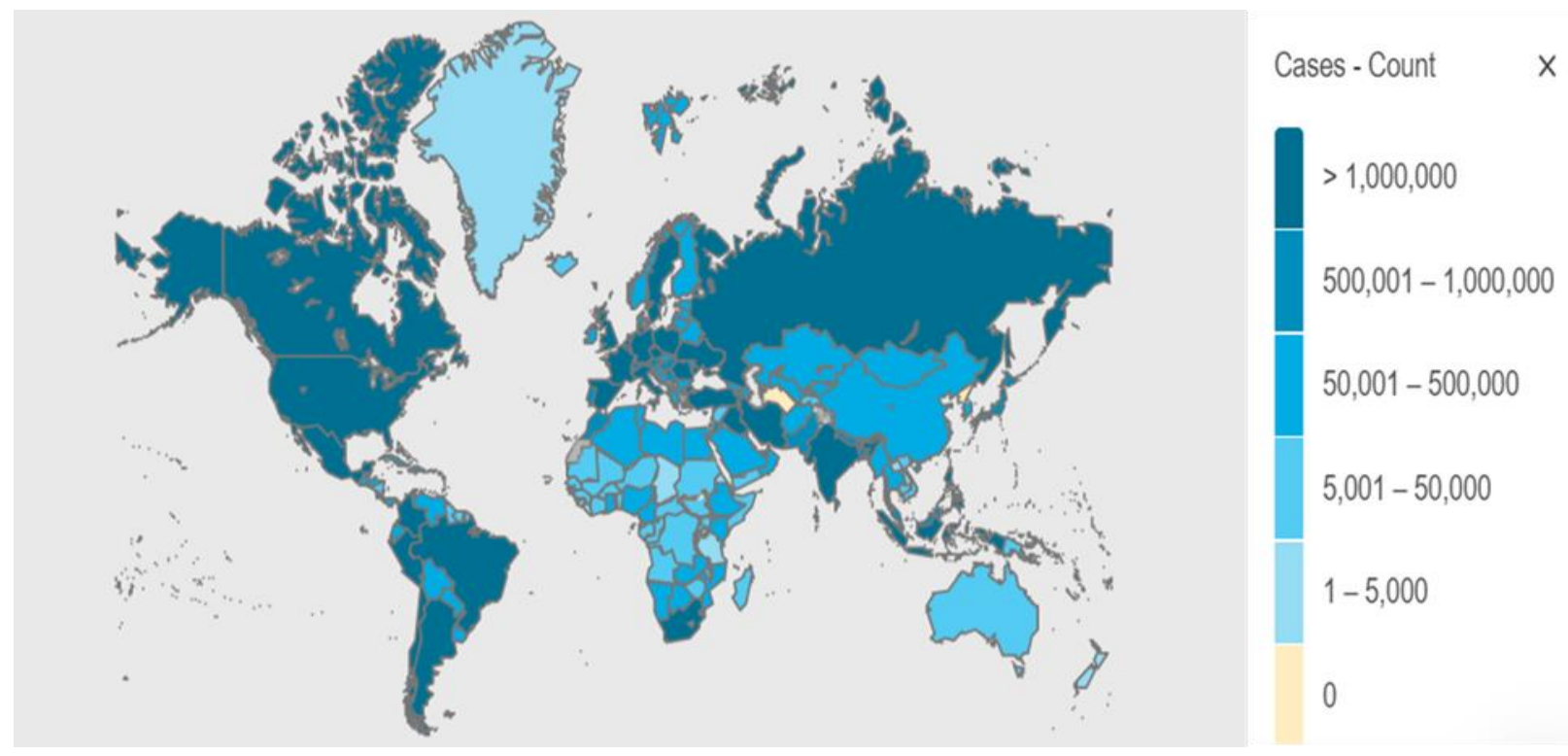

Şekil 1. Dünya genelinde vaka sayılarının yoğunluğu (WHO, 2021)

Bulaşıcı hastalıkların yayılmasının durdurulması veya sağlık sistemine gerekli zamanın kazandırılması için en azından yayılma hızının azaltılması adına kullanılan, karantina, antiviral ilaç, kapanma/kısıtlama, aşılama gibi çeşitli müdahale stratejileri bulunmaktadır. Bunların arasında en etkili yöntem aşılamadır (Siegrist, 2008). COVID-19 salgını yaklaşık bir buçuk yıldır etkisini sürdürürken, geliştirilen aşılar birçok topluma sürü bağışıklığ kazandırabilecek sayılarda üretilip dağıtılamamıştır. Bununla beraber başta Moderna, Biontech ve Sinovac olmak üzere birçok aşının iki hatta üç doz halinde uygulanması, önemli sayıda bireyin aşıya ulaşımını daha da güçleştirmektedir. Aşıların birden çok doz halinde uygulanma sebebi, belli bir zaman aralığında etkinlik derecelerini (efficacy level or rate) maksimum seviyelere çıkarmak ve koruyuculuklarını artırmaktır. Fakat toplumların önemli bir kesimi bir doz aşıya dahi ulaşamıyorken bazı kesimlere iki doz aşı yapılmak istenmesi tartışmaları da beraberinde getirmektedir. Bazı araştırmacılar tek dozda olsa mümkün olduğunca fazla kişinin aşı olmasını savunurken (Sinai, 2021; Goldberg, 2021; BBC News, 2021), bazı araştırmalarda tek doz aşının yeterli olmayacağı savunulmuştur (Bose, 2021; Gorvett, 2021; Goje, 2021).

$\mathrm{Bu}$ çalışmada yukarıdaki tartışmalar değerlendirilerek, Pfizer-Biontech aşısının aynı miktarlar için tek doz ve çift doz uygulanması halinde, farklı kapsama seviyeleri ve etkinlik dereceleri düşünülerek, toplam hasta ve ölüm sayılarını ne kadar düşürdüğü incelenmiştir. Pfizer-Biontech aşısının tek doz etkinlik düzeyi için farklı araştırmalarda farklı sonuçlara ulaşıldığ iç̧in hassasiyet analiziyle değerlendirilmiştir. Salgının modellenmesinde SIR (Korunmasız-Hasta-İyileşmiş) A $\breve{g}$ (Network) Temelli model kullanılmıştır. A $\breve{g}$ temelli modeller uzun yıllardır işgücü piyasalarının (Calvó-Armengol ve Jackson, 2007), uluslararası ticaretin (Chaney, 2014), finansal piyasaların (Elliott vd., 2014) modellenmesi gibi farklı çalışmalarda kullanılmıştır. Salgın hastalıkların modellenmesi de ağ temelli modellerin yapısına uygun olduğundan bu alanda yapılan çalışmalarda bulunmaktadır (Craig vd., 2020). Ağ temelli modelde, üretilen popülasyondaki bireyler birbirlerine direkt veya endirekt bağlantılı olabilmekte ve hastalık geçişleri bu örüntü üzerinden gerçekleşmektedir. Bireylerin birbirleriyle direkt veya endirekt bağlantısı sosyal çevreleriyle ilgilidir. Örnek olarak aynı evde yaşayan bireyler birbirleriyle direkt bağlantı kurabilmekteyken, bireylerin okullarındaki veya iş yerlerindeki arkadaşları, evdeki diğer bireylerle endirekt bağlantı kurmuş olur. Hastalığın geniş kesimlere yayılması endirekt bağlantılarla gerçekleşmektedir. Bulaşıcı hastalıkların yayılımının modellenmesinde kullanılan daha eski bir yöntem olan SIR bölmeli (compartmental) modellerde ise, popülasyondaki tüm bireylerin homojen olarak birbirleriyle ilişkili olduğu varsayımı yapılmıştır. Buna göre aynı evin içinde yaşayan bireylerin birbirleriyle etkileşime geçme olasılığı, şehrin bir ucunda yaşayan bireyle etkileşime geçme olasıllı̆ı ile aynı kabul edilmiştir. SIR bölmeli modeller birçok çalışmada kullanılmasına rağmen (Hethcote, 2000; Zaric ve Brandeau, 2001; Medlock ve Galvani, 2009), gerçek durumlara daha uygun olduğundan bu çalışmada SIR ağ temelli model kullanılmıştır.

Literatürde matematiksel SIR modellerinin yanı sıra, ağ temelli modellerin kullanıldığı çalışmalar bulunmaktadır. FluTE (Chao vd., 2010), EpiFire (Hladish vd., 2012), FRED (Grefenstette vd., 2013), SIMID (Ramírez-Ramírez vd., 2013) ve epiDMS (Liu vd., 2016) 
salgınları modellemek için geliştirilmiş ağ temelli yazılımlara örnek olarak sayılabilir. Sayılan yazılımlar incelenen salgınları doğru ve gerçekçi bir şekilde modellemelerine rağmen komplike yapıları nedeniyle üzerlerinde yapılmak istenen değişiklikler sınırlı kalmaktadır. Bazıları ara yüzlerinde bulunan belirli parametrelerde (iyileşme periyodu, $\mathrm{R}_{0}$ değeri, başlangıç hasta sayısı, popülasyon büyüklügü̈, vs.) değişiklik imkanı sunmasına rağmen, bu çalışmada düşünülen farklı ağ yapıları, çevresel faktörler, aşı müdahaleleri gibi önemli değişiklikleri yapmak mümkün değildir. Bazıları ise açık kaynak kodlu olmasına rağmen, içeriğinde büyük değişiklikler yapmak neredeyse yeniden yazmak kadar zor olacaktır. Son olarak çalışmamızda birçok senaryo için belirli sayılarda koşum yapılmış ve sonuçlar arasındaki farkların istatistiksel olarak anlamlı olup olmadığı test edilmiştir. Bunun için salgın modellemesini, gereken şartlara göre, görece hızlıca yapabilecek bir model geliştirilmeye ihtiyaç duyulmuştur.

Literatüre bakıldığında tek ve çift doz aşı uygulamasının hasta ve ölüm sayıları bakımından meydana çıkaracağı sonuçlar spekülasyondan öteye gidememiştir. Bu çalışmada modelleme ve benzetim teknikleri kullanılarak, Pfizer-Biontech aşısının farklı etkinlik düzeylerinde tek ve çift dozlarda, farklı sayılarda ve farklı zamanlarda dağııımının, hasta ve ölüm sayıları üzerine etkileri incelenmiştir. Amacımız karar vericilerin sınırlı aşı miktarları ve dağıtım zamanlarında, en doğru dağıtım kararını vermelerine yardımcı olmaktır.

Bir sonraki bölümde geliştirilen SIR ağ modeli ve benzetim için gerekli olan verilerle ilgili detaylı bilgi verilecektir. Bölüm 3’te benzetim bulguları açıklanacak, son bölümde ise sonuçlar tartışılarak, bazı varsayım ve sadeleştirmelerden bahsedilecektir.

\section{Materyal ve Yöntem}

\subsection{SIR Tabanlı A $\breve{g}$ Modelleri}

SIR, ingilizce Susceptible (Korunmasız), Infected (Hasta), Recovered (İyileşmiş) kelimelerinin baş harflerinden oluşan bir kısaltmadır. Korunmasız veya sağlklı olarak ifade edebileceğimiz bireyler, topluluk için henüz hasta olmamış ve hasta olma potansiyeli olanları ifade etmektedir. Sağlıklı ve hasta bireyler bir zaman aralığı boyunca kontağa geçebilir ve bu kontak sonucu sağlıklı bireylerde hasta olabilirler. Daha sonraki sürelerde bu yeni hasta olmuş bireylerde iyileşene kadar diğer sağlıklı bireylere hastalığ 1 yayabilirler. İyileşme sürecinde hasta bireyler ölebilir. İyileşen kişiler bir daha hasta olmaz ve hastalığı bulaştıramazlar. Matematiksel olarak modellenebilen klasik bir SIR modelinin en önemli ön kabulü, topluluk içindeki tüm bireylerin birbirleriyle etkileşim içine girmelerinin mümkün olmasıdır. Bir örnek verilecek olursa, şehrin bir ucunda yaşayan bir kişinin bir aile bireyi ile kontağa geçme olasıllı̆ının, şehrin diğer ucunda yaşayan hiç tanımadığı başka bir birey ile kontağa geçme olasılı̆̆ına eşittir. Gerçek hayatta bu durumu gözlemlemek çok güçtür. Bireyler çoğunlukla yakın çevresindeki bireylerle etkileşim içinde olmaktadır. Bu çevreler genellikle ev, okul, toplu taşıma araçları ve iş yerleridir. A $\breve{g}$ yapılarını temel alan modeller, kişilerin yakın çevrelerindeki bireylerle direkt, yakın çevrelerindeki kişilerin kendi çevrelerindeki bireylerle endirekt bağlantılar kurabilmesine olanak sağlarlar. Bulaş açısından bakılacak olursa, bireyler direkt bağlantılı olduğu bireylerden hastalık kapma riskine sahipken, endirekt olarak çevresindeki kişilerden de etkileneceklerdir. Örnek olarak bir evde sürekli kalan bir çocuk, çalışan bir ebeveyniyle direkt bağlantılıyken, ebeveyninin iş arkadaşlarıyla endirekt bağlantılı olur. İş yerinde hasta bireyler bulunması, bu bireylerle direkt bağlantısı olan ebeveynin hasta olmasına ve çocuğuna bulaştırmasına neden olabilecektir. SIR tabanlı ağ modelleri salgın hastalıkların gerçeğe yakın modellenmesinde çok daha başarılıyken, ağ yapıları kurmanın getirdiği yüksek işlem zamanlarından dolayı matematiksel modellemeler hala tercih edilmektedir (Demirbilek, 2021).

Çalışmamızda model dâhilinde üretilen bireylerin birbirleriyle kontağa geçebileceği üç farklı çevre tanımlanmıştır. Bunlar, çalışan bireylerin etkileşimde bulunabilecekleri iş yerleri, öğrencilerin etkileşime geçebilecekleri okullar ve yaşli, işsiz, çocuk ve ev hanımlarının gün içinde zaman geçirdikleri evlerdir. Sisteme tanımlanan her bir birey bir eve atanmak zorundadır. Modelde bir gün iki zaman dilimine ayrılmış, tüm bireyler ilk zaman dilimini evlerinde geçirirken, diğer zaman diliminde bazı bireyler okul ve iş yerlerinde, kalan bireyler ise evlerinde zaman geçirip, ortamlarındaki bireylerle etkileşim içinde olmaya devam ederler. Bu sayede bireyler arasında direkt ve endirekt bağlantılar kurulmuş olur. Anlatılanlar Şekil 2'de gösterilmiştir. 
Periyot 1
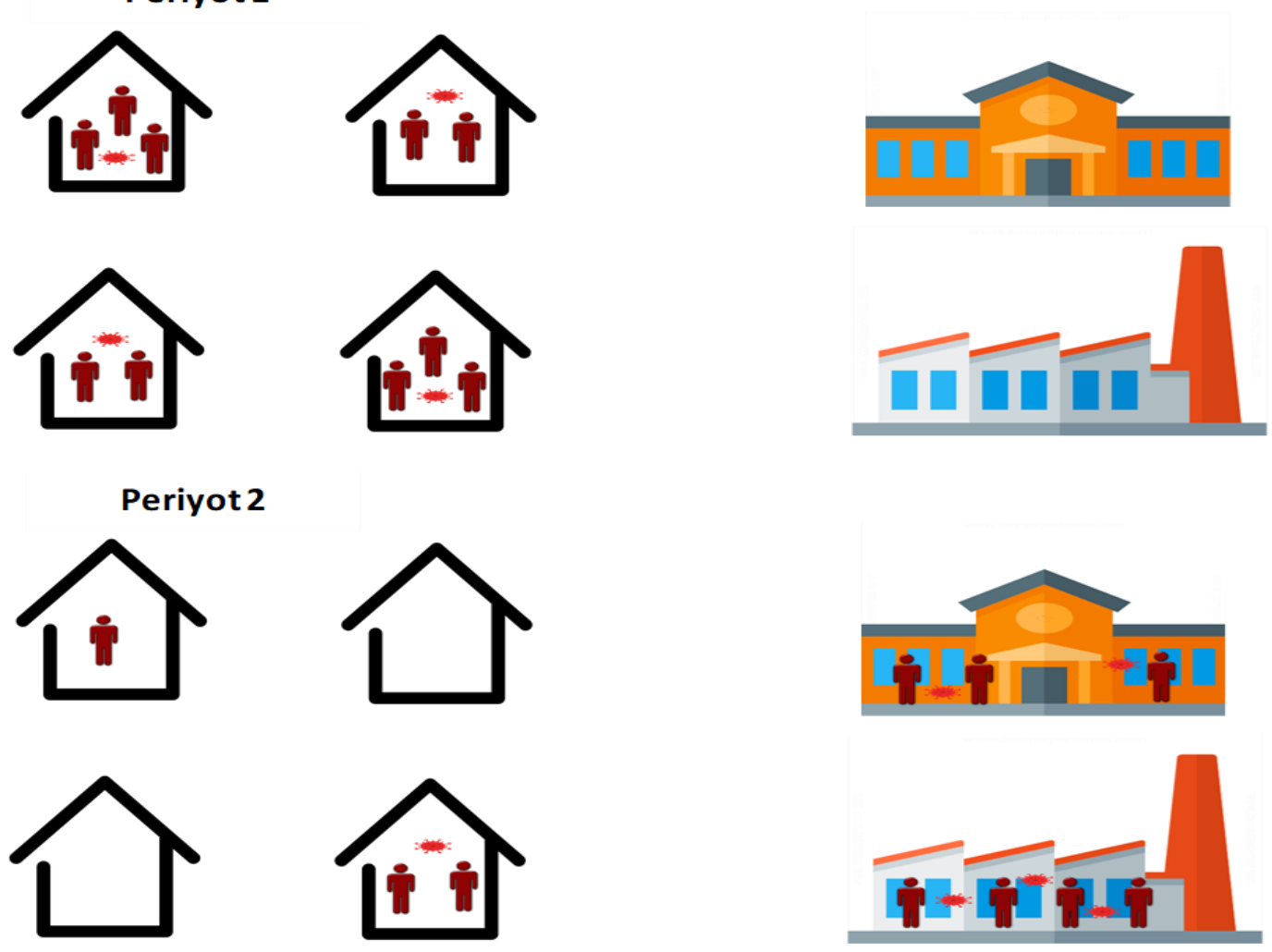

Şekil 2. Ağ temelli model (Network Model)

Hasta olmayan bir bireyin, bir zaman aralığında hasta olma olasılı̆̆ı, $p b$, Eşitlik 1'deki gibi hesaplanmaktadır (Demirbilek, 2021).

$$
p b=1-p^{n}
$$

0 ve 1 arasında değer alan $p$, bulaş şiddetine (attack rate) göre belirlenmektedir. Bireylerin bulunduğu ortamdaki (ev, iş yeri ve okul) hasta birey sayısını gösteren n sayısının yüksek olması, korunmasız bireyin enfekte olma olasılığını artırır. Hesaplanan enfekte olma olasılığı, 0 ve 1 arasında üretilen rastgele sayıdan büyük olması durumunda kişi hastalanır, küçükse korunmasız olarak kalmaya devam eder. Birey hasta olduktan sonra iyileşme periyodu belirtilen aralıklarda rastgele atanır. Hasta olduğu süre zarfında kişi, ortamı içinde bulunan sağlıklı bireyleri hasta edebilir. Enfekte olma ihtimali sadece sağlıklı kişiler içindir (Demirbilek, 2021).

\subsection{Benzetim Verileri}

Bu çalışma kapsamında 360 günlük salgın süreci düşünülmüştür. Salgının tepe noktası yaklaşık sürecin ortalarına düşmektedir. Tanımlı popülasyon, 0-4, 5-19, 20-24, 25-59, 60 ve üstü olmak üzere beş farklı yaş grubuna bölünmüştür. Nüfusun yaş gruplarına göre dağılımı 2019 TÜIKK verilerine göre yapılmıştır. 5-19 yaş grubundaki bireylerin ilköğretim ve lise çağındaki öğrenciler olduğu; 20-24 yaş aralığındaki bireylerin \%70'inin üniversite öğrencileri olduğu varsayılmıştır. 20-24 yaş aralığındaki bireylerin geriye kalanı ve 25-59 yaş grubundaki bireylerin \%85'inin çalıştığı düşünülmüş, geriye kalan yaş gruplarındaki bireylerin gün boyu evlerinde kaldığı varsayılmıştır. İyileşme periyodu her kişi için aynı olup, 6 ve 9 gün arasında düzgün dağılmıştır. Her koşum, rastgele olarak seçilmiş 15 hasta bireyle başlamaktadır. Evlerdeki birey sayıs 1 ve 7, iş yerlerindeki birey sayısı 50 ve 100, son olarak okullardaki birey sayısı 290 ve 310 arasında düzgün dağılıma sahiptir. Salgın şiddeti ve ölüm oranları Tablo 2'deki gibi gerçek verilere göre hesaplanmıştır. Aşılar salgının 30. günü dağıtılmaya başlanmış, her bir gün eşit olacak şekilde 60 ve 120 günlük dönemlerde dağıtımı yapılmıştır. Kapsama seviyesi, aşılanan bireylerin toplam birey sayısına oranı olarak tanımlanabilir. Bu çalışma kapsamında, \%10, \%20 ve \%30 olmak üzere üç farklı kapsama seviyesi uygulanmıştır. Bu kapsama seviyeleri iki doz aşı için geçerli olmakla beraber; tek doz aşı düşünüldüğünde bu seviyelerin iki katına çıkılmaktadır. Örnek olarak iki doz aşılama için 1 milyon kişilik bir nüfusun \%10'unun kapsanması hedeflenirse 200,000 aşı gerekecektir. Bu miktarda aşı tek doz halinde uygulandığında aynı nüfusun \%20'si kapsanacaktır.

Biontech aşısı için ilk doz etkinlik oranları için $\% 70, \% 75$ ve $\% 80$ olmak üzere üç farklı senaryo düşünülmüsşür. Bunun sebebi yapılan çalışmalarda ilk doz aşılama için farklı etkinlik oranları gözlenmesidir. Biontech aşısı için birinci ve ikinci aşılama arasındaki 3 haftalık süreçte aşının etkinlik oranı $\% 53$ olarak, ikinci dozdan sonraki bir haftalık süreçten sonra etkinlik oranının \%95'e çıktığı açıklanmıştır (Dawson, 2021). Bununla beraber tek doz aşının etkinlik oranının, uygulanmasından itibaren 4 haftalık süreç sonunda $\% 70$, \%74 ve 
\%80'lere çıktığı farklı ülkeler tarafından yapılan araştırmalarda ortaya konmuştur (Schuster-Bruce, 2021; Van Beusekom, 2021). Bu çalışmada tek doz için $\% 70, \% 75$ ve $\% 80$ olmak üzere üç farklı etkinlik oranı, iki doz için belirtilen \%95'lik etkinlik oranıyla karşılaştırılmıștır. Hem tek doz hem de iki dozluk uygulama için birinci ve ikinci doz arasındaki 21 günlük sürede etkinlik oranı $\% 53$ kabul edilmiştir. Daha sonra verilen maksimum etkinlik oranlarına bir haftalık süre boyunca lineer olarak ulaşıldığı varsayılmıştır. Benzetim ile ilgili gerekli veriler Tablo 1'de özet olarak gösterilmiştir.

Tablo 1. Benzetim verileri

\begin{tabular}{llll}
\hline Salgın şiddeti & $7.4 \%$ & Kapsama Seviyesi (\%) & $10,20,30$ \\
Ölüm Oranı & $2.1 \%$ & Dağıtım Zamanı (gün) & 60 ve 120 \\
Popülasyon (milyon) & 1 & Salgın Süresi (gün) & 360 \\
Başlangıç Hasta Sayısı & 15 & Aşılamanın Başlangıcı & 30. Gün \\
İyileşme Zamanı (gün) & Düzgün (6,9) & Okul (kişi) & Düzgün $(290,310)$ \\
Ev (kişi) & Düzgün (1,7) & İş yeri (kişi) & Düzgün $(50,100)$ \\
Etkinlik (Doz 1 ve 2) & $\% 53$ & Etkinlik Süresi (Gün) & 21 \\
$\begin{array}{l}\text { Maksimum Etkinlik } \\
\text { Doz) }\end{array}$ & $\% 95$ & Maksimum Etkinlik (1 Doz) & $\% 70, \% 75, \% 80$ \\
\hline
\end{tabular}

Salgın şiddeti (attack rate), tamamen korunmasız bir popülasyonda, belli bir süre sonunda hasta olan bireylerin toplam popülasyona oranı olarak tanımlanır. Modelimizde belirlenen çalışma süresi sonunda ortaya çıkan hasta ve ölü sayısının kalibrasyonunu, altı farklı ülkenin COVID-19 vaka ve ölüm sayılarına göre yapılmıştır. Baz alınan altı farklı ülkenin nüfusları, vaka ve ölü sayıları Tablo 2'de gösterilmiştir.

Tablo 2. Altı ülkenin COVID-19 vaka ve nüfus sayılarına göre bulaş şiddeti ve ölüm oranlarının hesaplanması [2]

\begin{tabular}{lllllc}
\hline Ülke & Nüfus & Vaka & $\begin{array}{c}\text { Bulaştırma } \\
\text { Şiddeti }\end{array}$ & $\begin{array}{c}\text { Ölümlü } \\
\text { Vaka }\end{array}$ & $\begin{array}{c}\text { Ölüm/Hasta } \\
\text { Oranı }\end{array}$ \\
\hline ABD & 331.002 .651 & 30.173 .235 & 0,091 & 598.597 & 0,020 \\
Almanya & 83.783 .942 & 3.243 .966 & 0,039 & 95.767 & 0,030 \\
İngiltere & 67.886 .011 & 5.146 .035 & 0,076 & 97.031 & 0,019 \\
Fransa & 65.273 .511 & 5.074 .276 & 0,078 & 89.957 & 0,018 \\
İspanya & 46.754 .778 & 4.289 .553 & 0,092 & 74.374 & 0,017 \\
İtalya & 60.461 .826 & 4.134 .479 & 0,068 & 92.850 & 0,022 \\
Oranlar & $\ldots$ & & $\mathbf{0 , 0 7 4}$ & $\ldots$ & $\mathbf{0 , 0 2 1}$ \\
\hline
\end{tabular}

Çalışma içinde iyileşme zamanı, evlere, okullara ve iş yerlerine atanan kişi sayıları, hastalığın bulaşma durumları gibi birçok stokastik veri kullanıldığından, 30 koşum için ortaya çıkan ortalama sonuçlar arasındaki farkın, istatistiksel olarak anlamlı olup olmadığını anlamak için bağımsız örneklem $t$ testleri uygulanmıştır. Modelimiz Python programlama diliyle kodlanmış, bütün koşumlar Intel i5 7200U $2.5 \mathrm{GHz}$ işlemcili ve $8 \mathrm{~GB}$ belleğe sahip Windows 10 işletim sistemi kurulu bir bilgisayarda gerçekleştirilmiştir.

\section{Bulgular}

Tablo 3 ve 4'de sırasıyla, 60 ve 120 günlük dağıtım zamanlarında, farklı aşı miktarları ve etkinlik seviyelerinde, tek doz ve iki doz aşılama için toplam hasta ve ölüm sayılarıyla, 30 koşum sonucu elde edilen ortalamalar arasındaki farkın, istatistiksel olarak anlamlı olup olmadığının anlaşılması için yapılan bağımsız örneklem t-testinin sonuçları gösterilmiştir. Testler için $\mathrm{H}_{0}$ hipotezi, iki ortalama değer arasında anlamlı bir farkın olmaması; alternatif hipotez ise değerlerin birbirinden farklı olmasıdır. Testlerin sonucunda ortaya çıan p değerleri, eşik değer olan 0.05 ile karşılaştırılmıştır. Eşik değerden küçük olan test değerleri $\mathrm{H}_{0}$ hipotezinin reddini; yani sonuçlar arasındaki farkın anlamlı olduğunu göstermektedir. Örnek olarak Tablo 3'e baktığımızda, aşıların iki doz olarak dağıtılmasından sonra ortaya çıkan hasta sayıları ile \%70 etkinlik seviyesinde tek doz olarak dağıtımıyla ortaya çıkan hasta sayıları için yapılan $t$ testinde ortaya çıan $p$ değeri 9.9E- 03 olmuştur. Bu sonuca göre aşıların 2 doz olarak uygulandığ senaryoda oluşan hasta sayısı, tek doz olarak uygulandığında ortaya çıkan hasta sayısından anlamlı olarak fazladır diyebiliriz.

Tablo 3, 60 günlük dağıtım zamanı için farklı dozlarda ve etkinlik seviyelerinde yapılan aşılamanın ve $t$ testlerinin sonuçlarını göstermektedir. Öncelikle tabloda yer alan "Aşısız" satırı herhangi bir aşılama stratejisi olmadan yapılan benzetimde toplam hasta ve ölüm sayılarını göstermektedir. Daha önceden de bahsedildiği gibi bu sayılar gerçek COVID-19 vaka ve ölüm sayılarına göre kalibre edilmiştir. Aşı miktarları toplam uygulanan doz adetlerini göstermektedir. İki doz aşı uygulandığı takdirde belirtilen sayıların yarısı 
kadar kişi aşılanmış olacaktır. İki yüz bin aşı çift doz halinde uygulandığında, bir milyon kişilik bir nüfus için \%10 kapsama sağlamaktadır. Hiç aşılama yapılmayan durumla kıyaslandığında vaka sayıları yaklaşık \%17 oranında azalmıştır. Tek doz aşılama için en küçük etkinlik seviyesi \%70 olarak belirlenmiştir. Bu seviyede dahi tek doz halinde uygulanan aşılama sonucu oluşan hasta ve ölü sayısı, çift doz uygulanma sonrası oluşan vaka sayılarından küçüktür. Çıkan sonuçlar arasındaki fark istatistiksel olarak anlamlıdır. Etkinlik düzeyi arttığında beklendiği gibi hasta ve ölüm sayıları da azalmaktadır. Sayılar arasındaki farklar, sadece tek ve çift doz arasındaki fark için değil, farklı etkinlik düzeylerindeki tek doz aşı uygulaması sonucu ortaya çıkan hasta ve ölü sayıları için de istatistiki olarak anlamlıdır. 60 günlük aşılama sürecinde sadece $\% 75$ ve $\% 80$ etkinlik oranlarındaki tek doz aşllamada sonuçlar birbirine yakındır. Aşı sayıları arttıkça sonuçlar arasındaki farklar daha belirgin olmaktadır. İki yüz bin aşı kullanıldığında \%70 etkinlik düzeyinde tek doz aşılama çift doz aşılamaya göre vaka sayılarını \%4 oranında azaltırken; aşı miktarı iki kat arttığında vaka sayıları \%7; üç kat arttığında ise vaka sayıları \%10 civarında azalmaktadır. Etkinlik oranı \%80 olduğunda, tek doz uygulama yapılması halinde vaka sayılarındaki azalma, sırasıyla $\% 11, \% 19$ ve $\% 22$ olmaktadır.

Tablo 3. Bir milyon kişilik nüfus için 60 gün boyunca dağıtılan farklı miktar, doz ve etkinlik oranlarındaki aşılamanın vaka sayılarına etkisi ve sonuçların anlamlılı̆ııı ölçmek için yapılan t testleri sonuçları

\begin{tabular}{|c|c|c|c|c|c|c|c|}
\hline \multirow{2}{*}{\begin{tabular}{r|} 
Aşı Miktarı \\
Aşısız
\end{tabular}} & & \multirow{2}{*}{$\begin{array}{l}\text { Hasta } \\
74.937\end{array}$} & \multirow{2}{*}{$\begin{array}{l}\text { Ölüm } \\
1.764\end{array}$} & \multicolumn{4}{|c|}{ Bağımsız Örneklem T-testleri } \\
\hline & $\ldots$ & & & $2 \mathrm{Doz}$ & $1 \mathrm{Doz}(\% 70)$ & $1 \mathrm{Doz}(\% 75)$ & $1 \mathrm{Doz}(\% 80)$ \\
\hline \multirow{4}{*}{200.000} & $2 \mathrm{Doz}$ & 57.763 & 1.325 & & $9,9 \mathrm{E}-03$ & $7,8 \mathrm{E}-07$ & $8,9 \mathrm{E}-10$ \\
\hline & $1 \mathrm{Doz}(\% 70)$ & 55.361 & 1.160 & 9,9E-03 & $\ldots$ & $7,1 \mathrm{E}-03$ & 4,4E-05 \\
\hline & $1 \mathrm{Doz}(\% 75)$ & 53.055 & 1.128 & $7,8 \mathrm{E}-07$ & 7,1E-03 & $\ldots$ & 2,7E-02 \\
\hline & $1 \mathrm{Doz}(\% 80)$ & 51.549 & 1.103 & $8,9 \mathrm{E}-10$ & $4,4 \mathrm{E}-05$ & 2,7E-02 & $\ldots$ \\
\hline \multirow{4}{*}{400.000} & $2 \mathrm{Doz}$ & 44.262 & 1.012 & $\ldots$ & $4,3 \mathrm{E}-05$ & $2,9 \mathrm{E}-14$ & $1,0 \mathrm{E}-18$ \\
\hline & $1 \mathrm{Doz}(\% 70)$ & 41.072 & 755 & $4,3 \mathrm{E}-05$ & $\ldots$ & $1,8 \mathrm{E}-08$ & $1,3 \mathrm{E}-13$ \\
\hline & $1 \mathrm{Doz}(\% 75)$ & 36.895 & 690 & $2,9 \mathrm{E}-14$ & $1,8 \mathrm{E}-08$ & $\ldots$ & 2,4E-02 \\
\hline & $1 \mathrm{Doz}(\% 80)$ & 35.784 & 684 & $1,0 \mathrm{E}-18$ & $1,3 \mathrm{E}-13$ & 2,4E-02 & $\ldots$ \\
\hline \multirow{4}{*}{600.000} & $2 \mathrm{Doz}$ & 34.899 & 768 & $\ldots$ & $7,6 \mathrm{E}-08$ & $2,1 \mathrm{E}-18$ & $3,6 \mathrm{E}-22$ \\
\hline & $1 \mathrm{Doz}(\% 70)$ & 31.637 & 489 & $7,6 \mathrm{E}-08$ & $\ldots$ & 6,7E-07 & $5,8 \mathrm{E}-12$ \\
\hline & $1 \mathrm{Doz}(\% 75)$ & 29.010 & 478 & $2,1 \mathrm{E}-18$ & 6,7E-07 & $\ldots$ & $9,8 \mathrm{E}-05$ \\
\hline & $1 \mathrm{Doz}(\% 80)$ & 27.267 & 460 & $3,6 \mathrm{E}-22$ & $5,8 \mathrm{E}-12$ & $9,8 \mathrm{E}-05$ & $\ldots$ \\
\hline
\end{tabular}

Tablo 4, 120 günlük dağıtım zamanı için farklı dozlarda ve etkinlik seviyelerinde yapılan aşılamanın ve t testlerinin sonuçlarını göstermektedir. Altmış günlük dağıtım zamanıyla kıyaslandığında, vaka sayılarının biraz daha yükseldiği görünmektedir. Bazı durumlarda çift doz ve tek doz aşılama sonucu oluşan vaka sayıları arasındaki farklar istatistiksel olarak anlamlı değildir. Örneğin 200.000 doz aşı için çift doz veya tek doz uygulanması sonuçları etkilememiştir. Benzer şekilde 400.000 aşı için, etkinlik oranlarının $\% 70$ ve \%75 olmasının vaka sayılarına anlamlı bir etkisi gözlenmemiştir. Diğer sonuçlar arasındaki farklar p değerlerinden gözükeceği üzere istatistiksel olarak anlamlıdır. Sırasıyla $\% 70, \% 75$ ve $\% 80$ etkinlik seviyelerinde tek doz aşı uygulamalarının, çift doz aşı uygulamasıyla karşılaştırıldı̆̆ında vaka sayılarını iki yüz bin doz için $\% 0.5$ (anlamlı değil), \%5, \%9, dört yüz bin doz için $\% 9, \% 12$, $\% 16$ ve altı yüz bin doz için $\% 10, \% 16, \% 21$ oranlarında düşürdüğü gözlemlenmiştir.

Tablo 4. Bir milyon kişilik popülasyon için 120 gün boyunca dağıtılan farklı miktar, doz ve etkinlik oranlarındaki aşılamanın vaka sayılarına etkisi ve sonuçların anlamlılığını ölçmek için yapılan $t$ testleri sonuçları

\begin{tabular}{|c|c|c|c|c|c|c|c|}
\hline \multicolumn{2}{|l|}{ Așı Miktarı } & \multirow{2}{*}{$\begin{array}{l}\text { Hasta } \\
74.937\end{array}$} & \multirow{2}{*}{$\begin{array}{l}\text { Ölüm } \\
1.764\end{array}$} & \multicolumn{4}{|c|}{ Bağımsız Örneklem T-testleri } \\
\hline AşısıIZ & $\ldots$ & & & $2 \mathrm{Doz}$ & $1 \mathrm{Doz}(\% 70)$ & $1 \mathrm{Doz}(\% 75)$ & $1 \mathrm{Doz}(\% 80)$ \\
\hline \multirow{4}{*}{200.000} & $2 \mathrm{Doz}$ & 59.105 & 1.364 & $\ldots$ & $3,5 \mathrm{E}-01$ & $4,3 \mathrm{E}-04$ & $8,8 \mathrm{E}-09$ \\
\hline & $1 \mathrm{Doz}(\% 70)$ & 58.770 & 1.244 & $3,5 \mathrm{E}-01$ & $\ldots$ & $4,2 \mathrm{E}-03$ & $1,0 \mathrm{E}-06$ \\
\hline & $1 \mathrm{Doz}(\% 75)$ & 56.072 & 1.203 & $4,3 \mathrm{E}-04$ & $4,2 \mathrm{E}-03$ & $\ldots$ & $7,5 \mathrm{E}-04$ \\
\hline & $1 \mathrm{Doz}(\% 80)$ & 53.744 & 1.159 & $8,8 \mathrm{E}-09$ & $1,0 \mathrm{E}-06$ & $7,5 \mathrm{E}-04$ & $\ldots$ \\
\hline \multirow[b]{2}{*}{400.000} & $2 \mathrm{Doz}$ & 48.095 & 1.093 & $\ldots$ & 2,3E-06 & $1,1 \mathrm{E}-11$ & $4,3 \mathrm{E}-16$ \\
\hline & 1 Doz (\%70) & 43.957 & 838 & 2,3E-06 & $\ldots$ & $1,3 \mathrm{E}-02$ & $3,2 \mathrm{E}-06$ \\
\hline
\end{tabular}

Tablo 4 (devam). Bir milyon kişilik popülasyon için 120 gün boyunca dağıtılan farklı miktar, doz ve etkinlik oranlarındaki aşılamanın vaka sayılarına etkisi ve sonuçların anlamlılı̆̆ını ölçmek için yapılan t testleri sonuçları 


\begin{tabular}{cllllllll} 
Aşı Miktarı & & Hasta & Ölüm & \multicolumn{3}{c}{ Bağımsız Örneklem T-testleri } \\
\hline \multirow{4}{*}{$\mathbf{4 0 0 . 0 0 0}$} & & & & & & & \\
& 1 & & & & & & \\
& $1 \mathrm{Doz}(\% 75)$ & 42.311 & 818 & $1,1 \mathrm{E}-11$ & $1,3 \mathrm{E}-02$ & $\ldots$ & $7,5 \mathrm{E}-04$ \\
& $1 \mathrm{Doz}(\% 80)$ & 40.323 & 796 & $4,3 \mathrm{E}-16$ & $3,2 \mathrm{E}-06$ & $7,5 \mathrm{E}-04$ & $\ldots$ \\
\hline \multirow{6}{*}{$\mathbf{6 0 0 . 0 0 0}$} & $2 \mathrm{Doz}$ & 39.449 & 885 & $\ldots$ & $2,1 \mathrm{E}-08$ & $5,0 \mathrm{E}-15$ & $8,7 \mathrm{E}-19$ \\
& $1 \mathrm{Doz}(\% 70)$ & 35.359 & 599 & $2,1 \mathrm{E}-08$ & $\ldots$ & $2,9 \mathrm{E}-04$ & $4,3 \mathrm{E}-08$ \\
& $1 \mathrm{Doz}(\% 75)$ & 32.992 & 575 & $5,0 \mathrm{E}-15$ & $2,9 \mathrm{E}-04$ & $\ldots$ & $5,4 \mathrm{E}-03$ \\
& $1 \mathrm{Doz}(\% 80)$ & 31.308 & 573 & $8,7 \mathrm{E}-19$ & $4,3 \mathrm{E}-08$ & $5,4 \mathrm{E}-03$ & $\ldots$ \\
\hline
\end{tabular}

\section{Sonuç ve Tartışma}

İnsanlık tarihi boyunca bulaşıcı hastalıklar medeniyetleri etkilemiş, çok sayıda insanın hasta olmasına ve hayatını kaybetmesine neden olmuşlardır. Son olarak dünyayı etkisi altına alan COVID-19 salgını şimdiye kadar milyonlarca insanın hastalanmasına ve ölmesine neden olmuş, bunun yanında yarattığı büyük iş gücü kayıpları, üretim faaliyetlerindeki aksamalar, arz talep dengesindeki bozulmalar yüzünden birçok ülke ekonomik krizlerle boğuşmak zorunda kalmıştır. Salgının başlamasından itibaren yapılan aşı çalışmaları meyvelerini vermeye başlamış olsa da, üretilen aşı miktarı hala gerekenin çok altındadır. Biontech, Moderna, Sinovac gibi önde gelen aşı üreticilerinin COVID-19'a karşı geliştirdiği aşı, etkinlik oranlarını mümkün olduğu kadar yukarı taşımak için iki doz halinde uygulanmaktadır. Son yapılan çalışmalarda, aşılar tek doz uygulandığı takdirde, yine önemli oranlarda etkinlik sağladığı görülmüştür. $\mathrm{Bu}$ da, kıt olan aşı kaynaklarını daha iyi kullanmak ve daha fazla insanın aşıya erişimini mümkün kılmak adına aşıların tek doz uygulanması gerektiği tartışmalarını beraberinde getirmiştir. Bu çalışmada, Biontech aşısının çift doz ve farklı etkinlik oranlarında tek doz olarak uygulandığında, toplam hasta ve ölüm sayını nasıl etkileyeceği konu alınmıştır. Salgının modellenmesi için SIR (Korunmasız-Hasta-İyileşen) Ağ (Network) modeli geliştirilmiş̧ir. Bir yıllık bir salgın süreci ve bir milyon kişilik bir nüfusun düşünüldüğü modelimiz, birçok stokastik parametre içerdiğinden, her senaryo için 30 koşum yapılmış ve çıkan sonuçlar arasındaki farkın istatistiksel olarak anlamlı olup olmadığını anlamak için bağımsız örneklem $t$ testleri uygulanmıştır.

Sonuçlar 60 ve 120 günlük dağııım süreçleri düşünülerek değerlendirilmiştir. Her dağıtım süreci için iki yüz, dört yüz ve altı yüz bin doz aşı mevcudiyeti düşünülmüştür. Altmış günlük dağıtım zamanı için bütün doz mevcudiyetlerinde, tek doz aşı dağıtımı iki doza göre daha düşük vaka sayıları sağlamıştır. Doz miktarları arttıkça sonuçlar arasındaki farklar orantısal olarak artmaktadır. Yapılan $t$ testi sonuçlarına göre sonuçlar arasındaki farklar ekseriyetle istatistiksel olarak anlamlıdır. 120 günlük dağıtım zamanı için de tek doz aşı uygulaması iki doza göre vaka sayılarını düşürmesine rağmen, iki yüz bin dozluk uygulama için sonuçlar arasında anlamlı bir fark bulunmamaktadır. Bunun yanında bazı etkinlik oranları için sonuçlar anlamlı değildir. Ancak genel olarak sonuçlara bakıldığında tek doz aşı uygulaması aşağıda belirtilen varsayımlar da göz önüne alınmak şartıyla iki doz aşı uygulamasına göre hasta ve ölüm sayılarını azalttığını söyleyebiliriz. Karar vericiler açısından baktığımızda, özellikle aşı sayısı, uygulanacak kişi sayısına oranla kısıtlı olduğunda tek toz aşı uygulaması tavsiye edilebilir. Herkesin bir dozda olsa aşılanabilmesi, sürü bağışıklığına daha hızlı ulaşmak adına büyük önem arz etmektedir. Yeni bir virüse karşı geliştirilen aşıların test, üretim ve dağıtım süreçlerinin önemli vakit alması, salgının ilk dönemlerinde insanların aşıya ulaşımını zorlaştırmaktadır. Daha sonraki süreçlerde geliştirilen aşıların farklı bölgelerde ve yüksek miktarlarda üretilebilmesi ve dağıtım kanallarının genişletilmesi, muhakkak aşıya erişimi daha kolaylaştıracaktır. Bu nedenle, başlangıçta tek dozda olsa fazla kişiye aşısının ulaştırılabilmesi, yeterli aşı sayılarına ulaşıldığında ise ikinci dozların uygulanması makul bir seçenek olarak görünmektedir.

Çalışmamızdaki en önemli ön kabuller aşı çalışmalarının çok yeni olmasından ileri gelmektedir. Özellikle tek ve çift doz için kabul edilen etkinlik oranları ve bu etkinlik oranlarına ulaşılacak sürelerle ilgili farklı sonuçlar bulunmaktadır. Özellikle tek doz aşı için kabul edilen etkinlik düzeylerine ulaşma süresi ile ilgili çok net bilgilere ulaşılamamıştır. Bu yüzden iki doz için belirtilen etkinlik oranına ulaşma zamanı, tek doz aşı için de aynı kabul edilmiştir. Ayrıca tek doz aşı uygulanan bireyler için hastanelik olma ve ölüm olasılıkları ile ilgili araştırmalara ulaşılamadığından, çift doz için kabul edilen veriler kullanılmıştır. Son olarak, model ile ilgili, kişilerin birbirleriyle etkileşime geçtiği yerler olarak sadece ev, okul ve işyerinin düşünülmesi, hastalık geçiş olasılığının yaşa, kronik hastalığa ve başka faktörlere bakılmadan her birey için eşit kabul edilmesi gibi varsayımlar yapılmıştır. Gelecek çalışmalarda dağıtılacak aşıların, kişilerin yaşına, kronik hastalığına, mesleğine göre, vaka sayılarını minimuma indirecek şekilde optimize edilmesini içeren çözüm yöntemleri geliştirilebilir.

\section{Referanslar}

BBC News, "One Covid vaccine cuts infection rate in all age groups", BBC News, 23 Nisan 2021, Available: https://www.bbc.com/news/health-56844220, [Accessed: 2 Eylül 2021]. 
Calvó-Armengol A. and Jackson M. O. (2007). Networks in labor markets: Wage and employment dynamics and inequality, J. Econ. Theory, 132(1), 27-46. Doi.org/10.1016/j.jet.2005.07.007

Carey Goldberg, "COVID-19 survivors may need just one shot of a two-dose vaccine", The Japan Times, 18 Nisan 2021, Available: https://www.japantimes.co.jp/news/2021/04/18/world/coronavirus-vaccine-doses/, [Accessed: 2 Eylül 2021].

Catherine Schuster-Bruce, "How much protection you get from one shot of the Pfizer, AstraZeneca, and Moderna vaccines, according to the best available data", Insider, 9 Temmuz 2021, https://www.businessinsider.com/covid-vaccine-one-shot-effectiveness-pfizermoderna-astrazeneca-vaccines-dose-2021-3, [Accessed: 2 Eylül 2021].

Cedars Sinai, "COVID-19 Survivors Might Need Just One Dose of Two-Part Vaccine", Cedars Sinai, 1 Nisan 2021, Available: https://www.cedars-sinai.org/newsroom/covid-19-survivors-might-need-just-one-dose-of-two-part-vaccine/, [Accessed: 2 Eylül 2021].

Chaney T. (2014). The network structure of international trade, Am. Econ. Rev., 104(11), 3600-3634. DOI: 10.1257/aer.104.11.3600

Chao, D.L., Halloran, M.E., Obenchain, V.J. and Longini Jr, I.M., (2010). FluTE, a publicly available stochastic influenza epidemic simulation model. PLoS computational biology, 6(1), 1-8. DOI: 10.1371/journal.pcbi.1000656

Craig B. R., Phelan T., Siedlarek J. P., and Steinberg J. (2020). Improving Epidemic Modeling with Networks, Econ. Comment. (Federal Reserv. Bank Cleveland), 1-8. DOI: 10.26509/frbc-ec-202023

Demirbilek M. (2020). YAYsim: Salgın Modelleme ve Karar Destek Sistemi, Bilecik Şeyh Edebali Üniversitesi Fen Bilim. Dergisi, 7(1), 104-112. DOI: 10.35193/bseufbd.675734

Demirbilek, M. (2021). The Effect of School/Workplace Closures on COVID-19 Related Incidents. Avrupa Bilim ve Teknoloji Dergisi, (23), 62-69. Doi.org/10.31590/ejosat.842793

Demirbilek, M. (2021). Tam ve Kısmi Kapanma Stratejilerinin COVID-19 Salgını Üzerinden Karşılaştırılması. El-Cezeri, 8 (2) , $1024-$ 1034, DOI: 10.31202/ecjse.909927.

Elliott M., Golub B., and Jackson M. O. (2014). Financial networks and contagion, American Economic Review, 104(10), 3115-3153. DOI: 10.1257/aer.104.10.3115

Grefenstette, J.J., Brown, S.T., Rosenfeld, R., DePasse, J., Stone, N.T., Cooley, P.C., Wheaton, W.D., Fyshe, A., Galloway, D.D., Sriram, A. and Guclu, H., (2013). FRED (A Framework for Reconstructing Epidemic Dynamics): an open-source software system for modeling infectious diseases and control strategies using census-based populations. BMC public health, 13 (1), 940. DOI: $10.1186 / 1471-2458-13-940$

Hethcote, H.W. (2000). The mathematics of infectious diseases, SIAM review, 42(4), 599-653. Doi.org/10.1137/S0036144500371907

Hladish, T., Melamud, E., Barrera, L.A., Galvani, A. and Meyers, L.A., (2012). EpiFire: An open source C++ library and application for contact network epidemiology. BMC bioinformatics, 13(1), 76. DOI: 10.1186/1471-2105-13-76

Joydeep Bose, "Covid-19 vaccine: One dose isn't enough. Govt explains why you need both", India News, 16 Nisan 2021, Available: https://www.hindustantimes.com/india-news/covid19-vaccine-one-dose-isn-t-enough-govt-explains-why-you-need-both-

101618552568387.html, [Accessed: 2 Eylül 2021].

Lindsey Dawson, "What Does a Multi-Dose Series Mean for the COVID-19 Vaccination Effort?", KFF, 5 Şubat 2021, https://www.kff.org/coronavirus-covid-19/issue-brief/what-does-a-multi-dose-series-mean-for-the-covid-19-vaccination-effort/,

[Accessed: 2 Eylül 2021].

Liu, S., Poccia, S., Candan, K.S., Chowell, G. and Sapino, M.L., (2016). epiDMS: data management and analytics for decision-making from epidemic spread simulation ensembles. The Journal of infectious diseases, 214, 427-432. DOI:10.1093/infdis/jiw305

Mary Van Beusekom, "Real-world trial of Pfizer COVID vaccine finds high 2-dose, good 1-dose protection", CIDRAP, 24 Şubat 2021, https://www.cidrap.umn.edu/news-perspective/2021/02/real-world-trial-pfizer-covid-vaccine-finds-high-2-dose-good-1-dose,

[Accessed: 2 Eylül 2021].

Medlock, J. and Galvani, A.P. (2009). Optimizing influenza vaccine distribution, Science, 325(5948), 1705-1708. DOI: $10.1126 /$ science. 1175570

Oluwatosin Goje, "Why It's Important to Get Your Second COVID-19 Vaccine Dose", Cleveland Clinic, 4 Mayis 2021, https://health.clevelandclinic.org/why-its-important-to-get-your-second-covid-19-vaccine-dose/, [Accessed: 2 Eylül 2021]. 
Ramírez-Ramírez, L.L., Gel, Y.R., Thompson, M., de Villa, E. and McPherson, M., (2013). A new surveillance and spatio-temporal visualization tool SIMID: SIMulation of Infectious Diseases using random networks and GIS. Computer methods and programs in biomedicine, 110(3), 455-470. DOI: 10.1016/j.cmpb.2013.01.007

Siegrist, C. A. (2008). Vaccine immunology. Vaccines, 5(1), 17-36.

Worldometers.info, "COVID19 Statistics", Worldometers, 24 May1s 2021, Available: https://www.worldometers.info/coronavirus/, [Accessed: 24 Mayis 2021].

WHO, https://covid19.who.int/, 24 Mayıs 2021.

Zaria Gorvett, "How effective is a single vaccine dose against Covid-19?", BBC Future, 15 Ocak 2021, Available: https://www.bbc.com/future/article/20210114-covid-19-how-effective-is-a-single-vaccine-dose, [Accessed: 2 Eylül 2021].

Zaric, G.S. and Brandeau, M.L. (2001). Resource allocation for epidemic control over short time horizons, Mathematical Biosciences, 171(1), 33-58. Doi.org/10.1016/S0025-5564(01)00050-5 